\title{
PENERAPAN DATAMINING DENGAN METODE KLASIFIKASI UNTUK STRATEGI PENJUALAN PRODUK DI UD.SELAMAT SELULAR
}

\author{
Sinta Maulina Dewi ${ }^{1}$, Agus Perdana Windarto ${ }^{2}$, Dedy Hartama ${ }^{3}$ \\ 1,2,3 Program Studi Sistem Informasi STIKOM Tunas Bangsa Pematang Siantar \\ Email: ${ }^{1}$ Sintamaulinadewi033@gmail.com, ${ }^{2}$ agus.perdana@amiktunasbangsa.ac.id
}

\begin{abstract}
Abstrak
Pada era globalisasi seperti saat ini, perkembangan di berbagai bidang usaha semakin cepat. Baik dalam bidang kuliner maupun bidang lainnya. Salah satu perkembangan bisnis yang paling di incar ialah dibidang counter atau penjualan pulsa. UD. Selamat Selular berdiri pada tahun 2010, yang hanya bermodalkan toko kecil tanpa karyawan hingga saat ini yang memiliki lebih dari 20 karyawan. Usaha ini tereus berkembang dalam persaingan bisnis yang terus meningkat. Maka dari itu diperlukan adanya strategi penjualan agar tidak kalah dari usaha dagang lainnya. Pada penelitian ini diperlukan adanya pengujian data sebelumnya agar dapat mengetahui strategi penjualan yang tepat dengan menggunakan naïve bayes. Metode pengumpulan data dilakukan dengan cara kuisioner dan wawancara dengan angket atas 160 responden. Dari hasil penelitian dapat disimpulkan bahwa model yang terbentuk menggunakan algoritma Naïve Bayes menghasilkan algoritma 0,650 sehingga tergolong sebagai Excellent Classification.
\end{abstract}

Kata Kunci: Datamining, Naïve Bayes, Strategi Penjualan.

\begin{abstract}
In the current era of globalization, developments in various fields of business are accelerating. Both in the culinary field and other fields. One of the most sought after business developments is in the field of counters or credit sales. UD.Selamat Selular was founded in 2010, which only has a small shop with no employees to date which has more than 20 employees. This business continues to develop in ever-increasing business competition. Therefore a sales strategy is needed so that it is not inferior to other trading businesses. In this research, it is necessary to test the previous data in order to find out the right sales strategy using Naïve Bayes. The data collection method was conducted by questionnaire and interview with a questionnaire of 160 respondents. From the results of this study it can be concluded that the model formed using the Naïve Bayes algorithm produces an algorithm of 0.650 so that it is classified as Excellent Classification.
\end{abstract}

Keywords: Datamining, Nä̈ve Bayes, Sales Strategy.

\section{PENDAHULUAN}

Penjualan merupakan sebuah usaha atau langkah konkrit yang dilakukan untuk memindahkan suatu produk. [1]. Dan Penjualan merupakan kegiatan yang dilakukan oleh suatu perusahaan dalam mempertahankan bisnisnya untuk berkembang dan mendapatkan laba atau keuntungan yang diinginkan. [2]. Pada era globalisasi seperti saat ini, perkembangan di berbagai bidang usaha semakin cepat. Baik dalam bidang kuliner maupun bidang lainnya. Salah satu perkembangan bisnis yang paling di incar ialah dibidang counter atau penjualan pulsa.

UD.Selamat Selular berdiri pada tahun 2010, yang hanya bermodalkan toko kecil tanpa karyawan hingga saat ini yang memiliki lebih dari 20 karyawan. Usaha ini terus berkembang dalam persaingan bisnis yang terus meningkat. Maka dari itu diperlukan adanya strategi penjualan agar tidak kalah dari usaha dagang lainnya.

Banyak cabang ilmu komputer yang dapat menyelesaikan masalah secara kompleks. Mereka diantaranya adalah sistem pendukung keputusan [3]-[7], datamining [8]-[11], sistem pakar [12], jaringan saraf tiruan [13]-[16], algoritma genetika [17] dan lain-lain. Cabang ilmu tersebut semuanya masuk kedalam artificial inteligence (AI). Berdasarkan permasalahan yang dihadapi, peneliti menggunakan teknik datamining klasifikasi untuk menyelesaikan permasalah sistem pembelajaran mahasiswa. Teknik datamining yang digunakana adalah Algoritma Nä̈ve Bayes. Diharapkan penelitian ini dapat memberikan masukan kepada pihak yang berkepentingan agar dapat mengetahui strategi penjualan produk di UD. Selamat Selular yang tepat dengan menggunakan teknik datamining.

\section{TEORITIS}

\subsection{Data Mining}

Data mining adalah proses menganalisa data dari perspektif yang berbeda dan menyimpulkannya menjadi informasi-informasi penting yang dapat dipakai untuk meningkatkan keuntungan, memperkecil biaya pengeluaran, atau bahkan keduanya. Secara teknis, data mining dapat disebut sebagai proses untuk menemukan korelasi atau pola dari ratusan atau ribuan field dari sebuah relasional database yang besar. [18][19][20].

\subsection{Naïve bayes}

Naive Bayes merupakan sebuah pengklasifikasian probabilistik sederhana yang menghitung sekumpulan probabilitas dengan menjumlahkan frekuensi dan kombinasi nilai dari dataset yang diberikan. Algoritma mengunakan teorema Bayes dan mengasumsikan semua atribut independen atau tidak saling ketergantungan yang diberikan oleh nilai pada variabel kelas.[21]. Naïve bayes juga digunakan oleh peneliti sebelumnya[22][23]. 


\subsection{RapidMiner}

RapidMiner adalah platform perangkat lunak ilmu data yang dikembangkan oleh perusahaan bernama sama dengan yang menyediakan lingkungan terintegrasi untuk persiapan data, pembelajaran mesin, pembelajaran dalam, penambangan teks, dan analisis prediktif

\section{ANALISA DAN PEMBAHASAN}

Berdasarkan penyederhanaan Naive Bayes bahwa nilai atribut secara kondisional saling bebas jika diberikan nilai output. Keuntungan dari menggunakan Naive Bayes adalah metode ini hanya membutuhkan jumlah data pelatihan (Training Data) yang kecil untuk menentukan estimasi paremeter yang diperlukan dalam proses pengklasifikasian. Dalam metode Naive Bayes data String yang bersifat konstan dibedakan dengan data numerik yang bersifat kontinyu, perbedaan ini akan terlihat pada saat menentukan[24]. Adapun penerapan dari Naïve Bayes sebagai berikut :

Tabel 1. Data Training

\begin{tabular}{rllllll}
\hline No & Harga & Cashback & Pelayanan & Kualitas Jaringan & Bonus & Penjualan \\
\hline 1 & Murah & Banyak & Baik & Baik & Tidak Ada & Tinggi \\
2 & Murah & Banyak & Baik & Buruk & Ada & Rendah \\
3 & Murah & Sedikit & Buruk & Baik & Ada & Rendah \\
4 & Murah & Sedikit & Baik & Baik & Ada & Tinggi \\
5 & Murah & Tidak Ada & Baik & Buruk & Ada & Rendah \\
6 & Normal & Banyak & Baik & Baik & Ada & Tinggi \\
7 & Normal & Sedikit & Buruk & Baik & Tidak Ada & Tinggi \\
8 & Normal & Tidak Ada & Baik & Baik & Ada & Tinggi \\
9 & Normal & Banyak & Baik & Buruk & Ada & Rendah \\
10 & Normal & Sedikit & Buruk & Buruk & Ada & Rendah \\
11 & Mahal & Banyak & Baik & Baik & Tidak Ada & Tinggi \\
12 & Mahal & Sedikit & Baik & Baik & Ada & Tinggi \\
13 & Mahal & Tidak Ada & Baik & Baik & Ada & Tinggi \\
14 & Mahal & Banyak & Buruk & Baik & Tidak Ada & Rendah \\
15 & Mahal & Sedikit & Baik & Buruk & Ada & Rendah \\
16 & Murah & Tidak Ada & Baik & Baik & Ada & Tinggi \\
17 & Murah & Tidak Ada & Baik & Buruk & Ada & Rendah \\
18 & Normal & Tidak Ada & Buruk & Baik & Tidak Ada & Tinggi \\
19 & Normal & Tidak Ada & Baik & Buruk & Ada & Rendah \\
160 & Mahal & Banyak & Buruk & Baik & Tidak Ada & Tinggi \\
\hline
\end{tabular}

Setelah didapat data diatas, maka langkah selanjutnya ialah menerapkan nya pada rapid miner. RapidMiner yang digunakan adalah RapidMiner 53.00. Adapun penerapannya sebagai berikut :

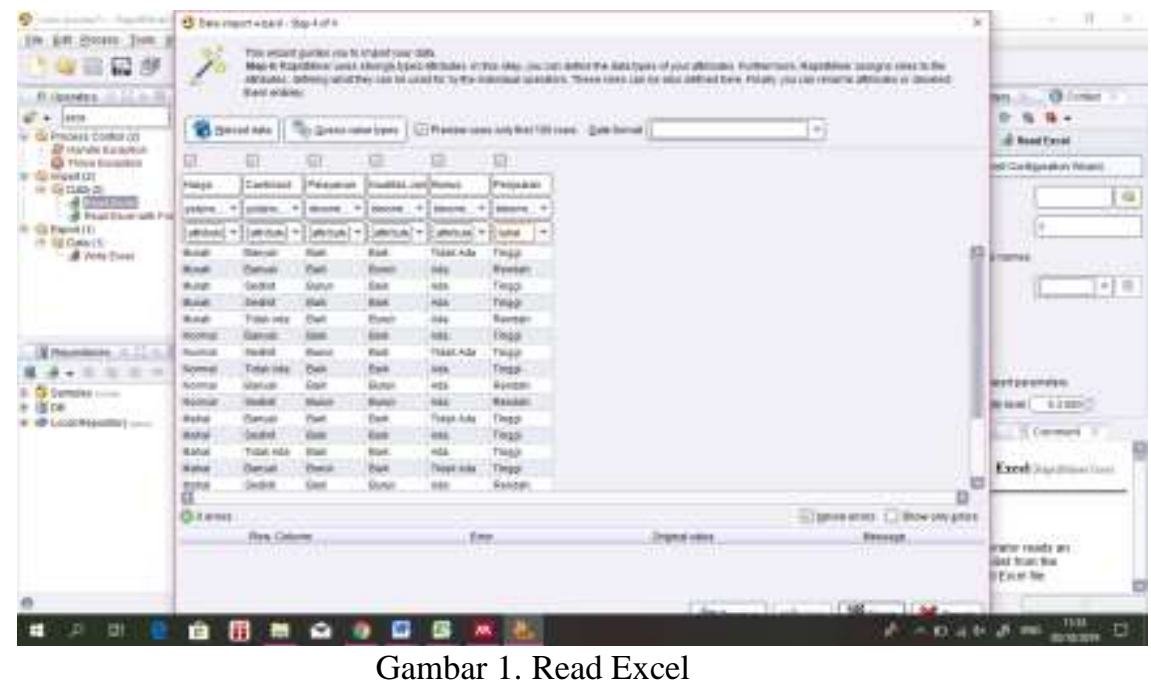

Pada Gambar 1 adalah data training yang akan kita uji. Selanjutnya data tersebut akan diuji sebagai berikut : 


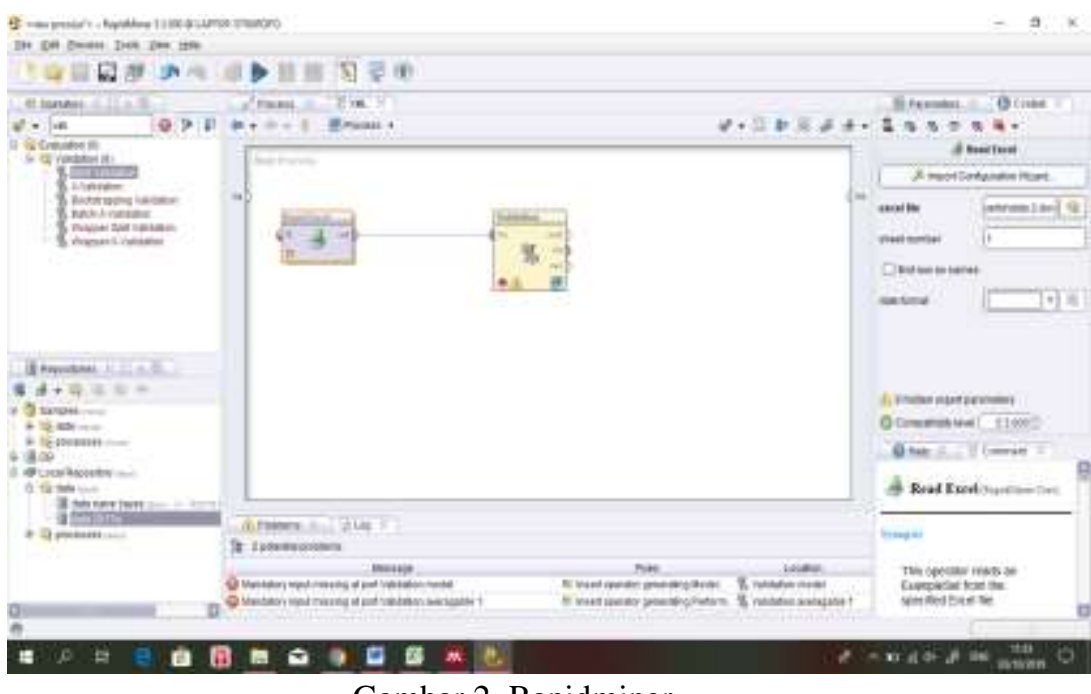

Gambar 2. Rapidminer

Pada Gambar 2, data yang telah kita import akan dihubungkan dengan validasi (spit validasi). Setelah terhubung, maka selanjutnya adalah proses antara metode dengan performance kemudian apply.

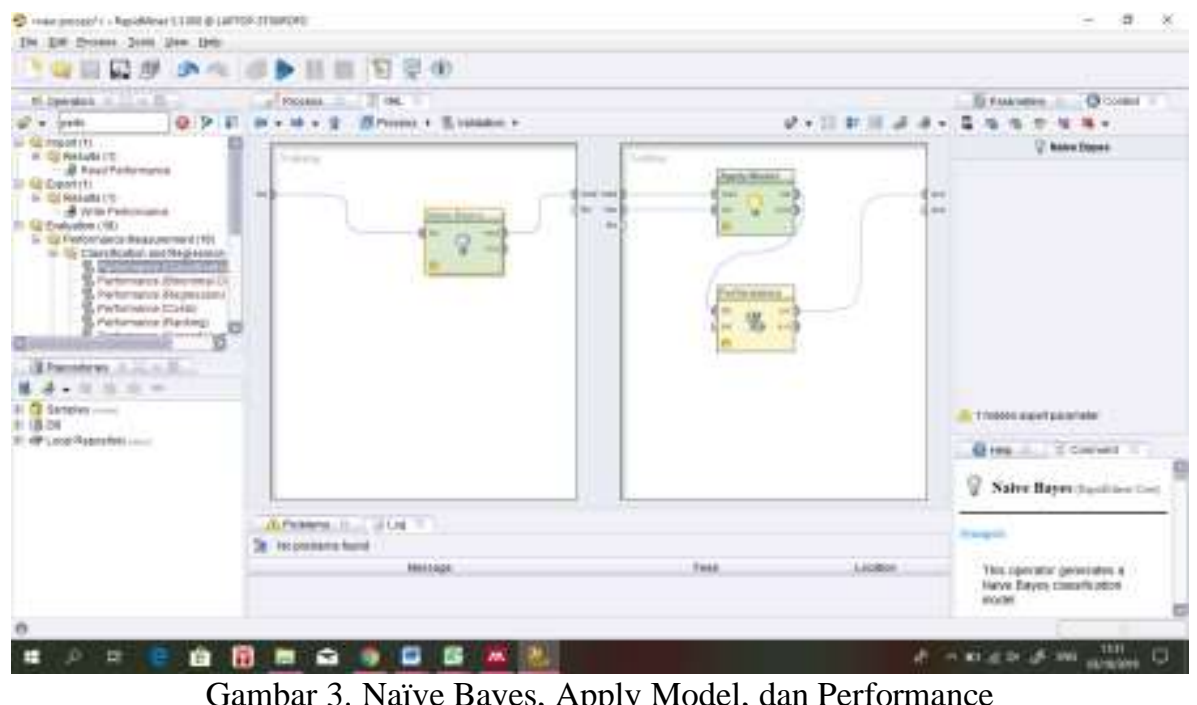

Pada Gambar 3, Semua bagian saling dihubungkan hingga membentuk sebuah relasi. Kemudian relasi tersebut kita proses. Adapun proses nya sebagai berikut :

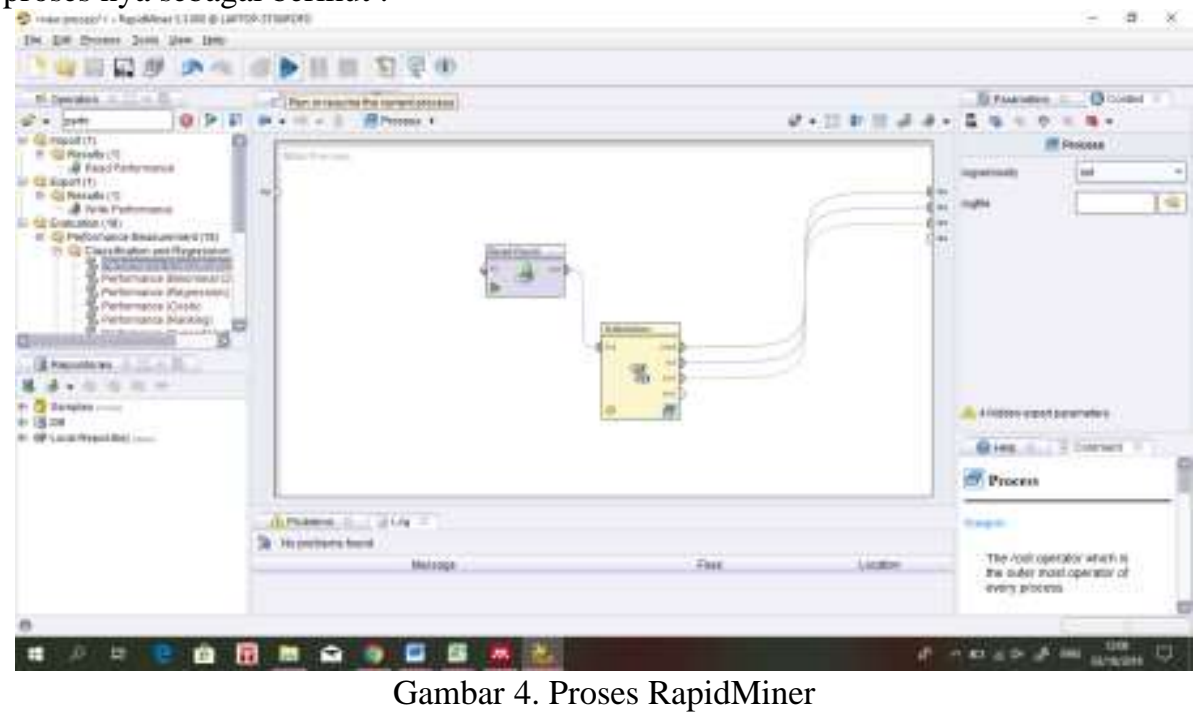

Data yang telah diproses akan menghasilkan sebagai berikut : 


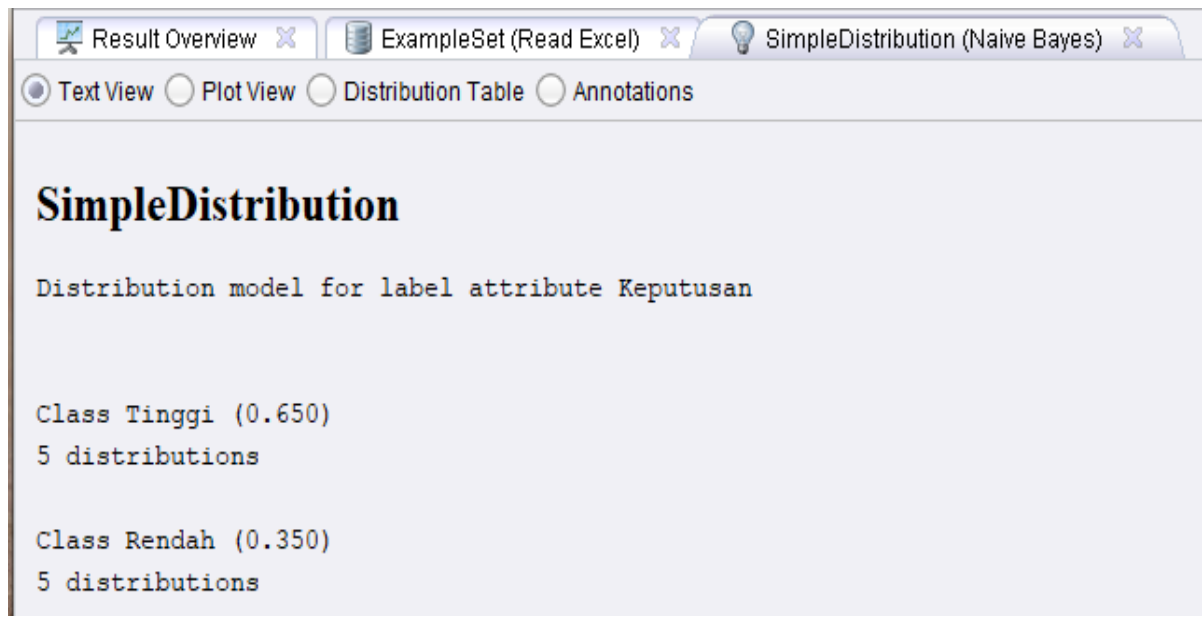

Gambar 5. Hasil dari uji dari data training dan testing

Gambar 5, merupakan hasil dari uji data training dan data testing. Yang menghasilkan 5 class tinggi, dan 5 class rendah dengan nilai 0,650 dan 0,350 .

\section{KESIMPULAN}

Dari hasil penelitian diatas dapat disimpulkan bahwa model yang terbentuk dengan menggunakan algoritma Naïve Bayes menghasilkan algoritma 0,650 sehingga tergolong sebagai Excellent Classification sehingga dapat disimpulkan algoritma Naïve Bayes dapat diterapkan untuk melakukan klasifikasi strategi penjualan produk.

\section{REFERENCES}

[1] B. A. B. Ii and T. Pustaka, "No Title," pp. 7-18.

[2] P. T. Damai, J. M. Pemasaran, U. K. Petra, and J. Siwalankerto, "No Title," vol. 2, no. 1, pp. 1-15, 2013.

[3] S. M. Dewi and A. P. Windarto, "Analisis Metode Electre Pada Pemilihan Usaha Kecil Home Industry Yang Tepat Bagi Mahasiswa," Sist. J. Sist. Inf., vol. 8, no. 3, pp. 377-385, 2019.

[4] D. R. S. P, A. A. Muin, and M. Amin, "PEMILIHAN FACIAL WASH UNTUK KULIT WAJAH BERMINYAK DENGAN METODE PROMETHEE II," CESS (Journal Comput. Eng. Syst. Sci., vol. 4, no. 2, pp. 222-229, 2019.

[5] C. Astria, A. P. Windarto, and Z. Musiafa, "PEMILIHAN PRODUK SAMPO SESUAI JENIS KULIT KEPALA DENGAN METODE PROMETHEE II," CESS (Journal Comput. Eng. Syst. Sci., vol. 4, no. 2, pp. 178-185, 2019.

[6] D. N. Batubara, A. P. Windarto, and M. R. Raharjo, "PENERAPAN PROMETHEE II PADA PEMILIHAN PRODUK CONDITIONER SEBAGAI UPAYA PENINGKATAN MINAT BELI KONSUMEN," CESS (Journal Comput. Eng. Syst. Sci., vol. 4, no. 2, pp. 191-197, 2019.

[7] D. N. Batubara, D. R. S. P, and A. P. Windarto, "Penerapan Metode PROMETHEE II Pada Pemilihan Situs Travel Berdasarkan Konsumen,” J. SISFOKOM, vol. 8, no. 1, pp. 46-52, 2019.

[8] A. P. Windarto, "Penerapan Datamining Pada Ekspor Buah-Buahan Menurut Negara Tujuan Menggunakan K-Means Clustering Method," Techno.Com, vol. 16, no. 4, pp. 348-357, 2017.

[9] M. G. Sadewo et al., "PENERAPAN ALGORITMA CLUSTERING DALAM MENGELOMPOKKAN BANYAKNYA DESA / KELURAHAN MENURUT UPAYA ANTISIPASI / MITIGASI BENCANA ALAM MENURUT PROVINSI DENGAN K-MEANS,” vol. 2, pp. 311-319, 2018.

[10] H. Siahaan, H. Mawengkang, S. Efendi, A. Wanto, and A. P. Windarto, "Application of Classification Method C4 . 5 on Selection of Exemplary Teachers," in IOP Conference Series, 2018, pp. 1-6.

[11] Sudirman, A. P. Windarto, and A. Wanto, "Data mining tools | rapidminer: K-means method on clustering of rice crops by province as efforts to stabilize food crops in Indonesia," IOP Conf. Ser. Mater. Sci. Eng., vol. 420, p. 12089, 2018.

[12] S. Azhar, H. Latipa, S. Leni, and N. Zulita, "Sistem Pakar Penyakit Ginjal Pada Manusia Menggunakan Metode Forward Chaining," J. Media Infotama, vol. 10, no. 1, pp. 16-26, 2014.

[13] T. Budiharjo, Soemartono, T., Windarto, A.P., Herawan, "Predicting tuition fee payment problem using backpropagation neural network model," Int. J. Adv. Sci. Technol., 2018.

[14] T. Budiharjo, Soemartono, T., Windarto, A.P., Herawan, "Predicting school participation in indonesia using back-propagation algorithm model," Int. J. Control Autom., 2018.

[15] A. P. Windarto, M. R. Lubis, and Solikhun, "MODEL ARSITEKTUR NEURAL NETWORK DENGAN BACKPROPOGATION PADA PREDIKSI TOTAL LABA RUGI KOMPREHENSIF BANK UMUM KONVENSIONAL," Kumpul. J. Ilmu Komput., vol. 5, no. 2, pp. 147-158, 2018.

[16] A. P. Windarto, M. R. Lubis, and Solikhun, "IMPLEMENTASI JST PADA PREDIKSI TOTAL LABA RUGI KOMPREHENSIF BANK UMUM KONVENSIONAL DENGAN BACKPROPAGATION," J. Teknol. Inf. dan Ilmu Komput., vol. 5, no. 4, pp. 411-418, 2018.

[17] Sumijan, A. P. Windarto, A. Muhammad, and Budiharjo, "Implementation of Neural Networks in Predicting the Understanding Level of Students Subject," Int. J. Softw. Eng. Its Appl., vol. 10, no. 10, pp. 189-204, 2016.

[18] J. Komputer et al., "PENERAPAN DATA MINING UNTUK MEMPREDIKSI Program Studi Teknik Informatika Jurnal 
Komputer dan Informatika ( KOMPUTA ),” 2012

[19] M. P. Tana, F. Marisa, I. D. Wijaya, J. T. Informatika, and F. T. U. Widyagama, "Penerapan Metode Data Mining Market Basket Analysis Terhadap Data Penjualan Produk Pada Toko Oase Menggunakan Algoritma Apriori," vol. 3, no. 2, pp. 1722, 2018

[20] A. P. Windarto, "Implementation of Data Mining on Rice Imports by Major Country of Origin Using Algorithm Using KMeans Clustering Method," Int. J. Artif. Intell. Res., vol. 1, no. 2, pp. 26-33, 2017.

[21] A. Saleh, "Implementasi Metode Klasifikasi Naïve Bayes dalam Memprediksi Besarnya Penggunaan Listrik Rumah Tangga," Citec J., vol. 2, no. 3, pp. 207-217, 2015.

[22] J. I. Informatika, “IMPLEMENTASI METODE KLASIFIKASI NAIVE BAYES UNTUK,” vol. 1, no. 1, 2016.

[23] E. Karyadiputra, S. Kom, and M. Kom, "ANALISIS ALGORITMA NAIVE BAYES UNTUK KLASIFIKASI STATUS KESEJAHTERAAN RUMAH TANGGA KELUARGA BINAAN SOSIAL,” vol. 7, no. 4, pp. 199-208, 2016.

[24] U. Gunadarma, “Konsep Data Mining,” 2009. 